\title{
Effects of tanacetum parthenium I hydroalcoholic extract on sexual hormones and some liver enzymes
}

\begin{abstract}
Introduction: Tanacetum parthenium L. is one of the most ancient and well-known medicinal plants that its role in the treatment of a wide range of diseases has been studied. This study assessed the probable effects of hydroalcoholic extract of Tanacetum parthenium L. on liver enzymes, including Alkaline phosphatase (ALP)/ Aspartate aminotransferase (AST). Furthermore sexual hormones (progesterone and estrogen) were evaluated in female mice.

Materials and methods: 40 female mice with the mean weight of 30-40 gr were divided into three groups: control, sham, and experimental groups control group did not receive any drug. Sham group only received normal saline. The experimental groups were injected by 25,50 , and $100 \mathrm{mg} / \mathrm{kg}$ doses of Tanacetum parthenium extract intraperitoneally for 15 consecutive days. Finally, animals were anesthetized using ether, blood serum was extracted and the serum concentration of AST, ALP, estrogen and progesterone was measured. Data were analyzed by one-way ANOVA.

Results: The mean serum level of estrogen and progesterone was significantly higher in the experimental groups 50 and $100 \mathrm{mg} / \mathrm{kg}$ compared to the sham and control groups. Serum levels of and AST and ALP indicated significant decrease only at 50 and $100 \mathrm{mg} / \mathrm{kg}$ doses of extract.

Conclusion: Active ingredients of Tanacetum parthenium L. may act as an antioxidant to decrease production of free radicals or liver enzymes releasing into the blood through stabilization of hepatocyte membrane. On the other hand, Tanacetum parthenium L. extract may have some effects on hormone concentration that is due to phytoestrogen components, and can increase the estrogen and progesterone levels.
\end{abstract}

Keywords: Tanacetum parthenium, Estrogen, Progesterone, ALP, AST, mice
Volume 8 Issue 2 - 2019

\author{
Ramezani M \\ Department of Biology, Islamic Azad University, Iran
}

Correspondence: Ramezani M, Department of Biology, Faculty of Science, Central Tehran Branch, Islamic Azad University, Tehran, Iran, Email mina.ramezani@gmail.com

Received: July 14, 2018 | Published: April 03, 2019

\section{Introduction}

Tanacetum Partenium L. a member of Asteraceae family is a daisy-like perennial plant. It was native to Eurasia, but cultivation has spread it around the world. It grows up to $0.6 \mathrm{~m}$ tall. Tanacetum P. is a medicinal plant traditionally used to reduce fever, so it is called feverfew. ${ }^{1}$ Feverfew has a consideration attention in the treatment of fevers, migraine headaches, rheumatoid arthritis, stomachaches, toothaches, insect bites, infertility, and problems with menstruation. ${ }^{2}$

The aerial parts of feverfew contain the sesquiterpene lactones. The predominant sesquiterpene lactone present in feverfew is parthenolide, which is among the most important biologically active component. In addition, different flavonoids like kaempferol, tanetin, luteolin and apigenin have been isolated from the extract. ${ }^{3}$ In addition to traditionally history, studies have indicated that feverfew is effective in migraine treatment. ${ }^{4}$ The feverfew extract is now used as tablet, capsule, and liquid forms by some patients who suffer of migraine. ${ }^{2}$ The hydroalcoholic extract also possess antioxidant constituents. ${ }^{5}$ Taking into consideration the large and daily usage of feverfew, we evaluated the effect of extract on liver enzymes. Measuring aspartate aminotransferase (AST or SGOT) and alkaline phosphatase (ALP) enzymes are two of the most sensitive and routine liver blood tests. These tests can be used to asses liver function or liver injury. When the liver is damaged, the liver cells release these enzymes into the blood. Increasing AST and ALP blood levels signaling liver disease. ${ }^{6}$ It is known that flavonoids are the most common group of polyphenolic compounds, which leads to several estrogen mimetic effects in humans. ${ }^{7}$ Therefore, on the other part of study, we examined the effect of feverfew extract on the rate of female sexual hormones to evaluate the folk uses of the plant as abortifacient, and emmenagogue.

\section{Materials and methods}

\section{Plant material}

Plants were collected from Shahrekord (Chaharmahal Bakhtiari province of Iran) in June during flowering season. All parts of plant including aerial parts and roots were dried in shadow and ground to a fine mixture. Then $40 \mathrm{~g}$ of powdered plant was extracted by Soxhelt apparatus using $70 \%$ ethanol for 24 hours. The solvent was distilled off using Oven under $50^{\circ} \mathrm{C}$. The prepared extract which equal to $5.23 \mathrm{~g}$ was kept in refrigerator at $4^{\circ} \mathrm{C}$ until use. For injections, the extract was freshly dissolved in normal saline to achieve appropriate concentrations.

\section{Animals}

Female NMRI mice weighing (25-30 g) were obtained from the Pasture Institute (Karaj, Iran). They were kept in plastic cages in standard environmental conditions $\left(22 \pm 2^{\circ} \mathrm{C}\right.$, humidity $60 \pm 5 \%, 12$ $\mathrm{h}$ light: $12 \mathrm{~h}$ dark cycle) with free access to pellet food and water following international recommendations. All animal experiments 
were done in accordance to the ethical regulations in the Guide for the care and Use of Laboratory Animals [8]. The animals were left for one week to adapt to the room conditions and then accidentally divided into five separated groups (6 in each) including; control, sham, 25, 50, and $100 \mathrm{mg} / \mathrm{kg}$ body wt. Doses of Tanacetum p. extract. All injections were done intraperitoneally and daily for 15 consecutive days. The sham group received the same volume of normal saline and control group received no injection.

\section{Hormone and enzyme assay}

At the end of treatment period, animals were sacrificed by decapitation and one milliliter of blood was collected from the each ventricle. Immediately after the blood collection, blood samples were obtained and the sera were separated by centrifugation at 12000 $\mathrm{rpm}$ and stored at $-20^{\circ} \mathrm{C}$ for the subsequent assays. Estrogen and progesterone levels were determined by Vidas assay. Liver enzymes (ALP and AST) were measured by ELISA method (Pars Azmon kit).

\section{Statistical analysis}

Statistical analysis was done by SPSS software, version 13. All results were expressed as mean \pm S.E.M. Statistical analysis were done using one-way ANOVA followed by Tukey-Kramer test. Values were considered significantly different at $\mathrm{p}<0.05$.

\section{Results}

\section{Effect of tanacetum parthenium hydroalcoholic extract on sexual hormones}

As it is shown in Figure 1 and 2, 50 and $100 \mathrm{mg} / \mathrm{kg}$ doses of Tanacetum $\mathrm{p}$. extract have increased estrogen and progesterone levels significantly in comparison with control and sham $(\mathrm{p}<0.01$ and $\mathrm{p}<0.001$ ) (Figure $3 \& 4$ ).

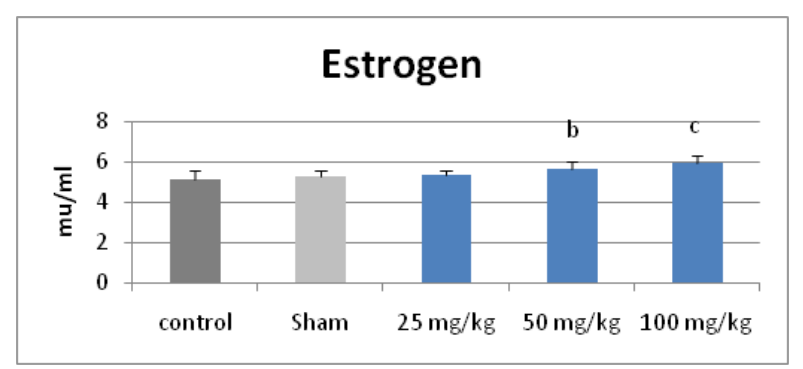

Figure I Effect of Tanacetum parthenium hydroalcoholic extract on serum estrogen levels in different groups of mice. Each value is expressed as the mean \pm S.E.M. of 6 animals. b $\mathrm{P}<0.0 \mathrm{I}$ and $\mathrm{c} P<0.00 \mathrm{I}$, compared to control and sham.

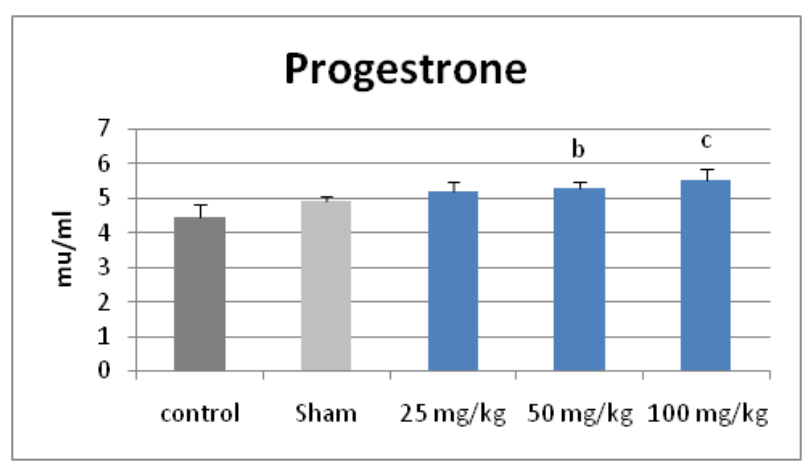

Figure 2 Effect of Tanacetum parthenium hydroalcoholic extract on serum progesterone levels in different groups of mice. Each value is expressed as the mean \pm S.E.M. of 6 animals. b $\mathrm{P}<0.0 \mathrm{I}$ and $\mathrm{c} \mathrm{P}<0.00 \mathrm{I}$, compared to control and sham.

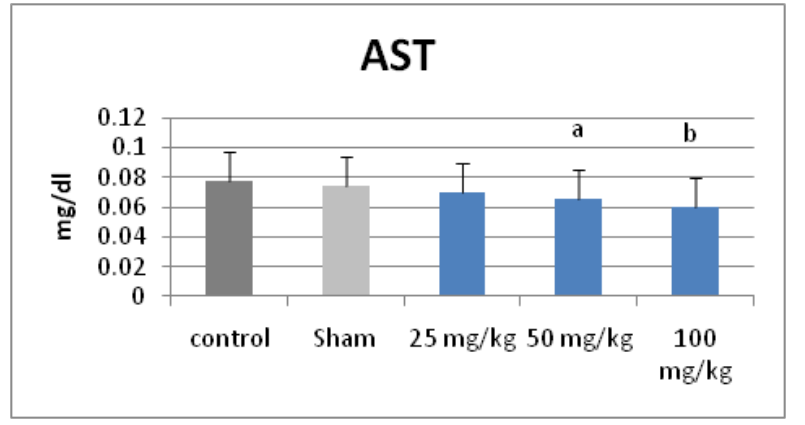

Figure 3 Effect of Tanacetum parthenium hydroalcoholic extract on Aspartate aminotransferase (AST) level in different groups of mice. Each value is expressed as the mean \pm S.E.M. of 6 animals. a $\mathrm{P}<0.05$ and $\mathrm{b} \mathrm{P}<0.0 \mathrm{I}$, compared to control and sham.

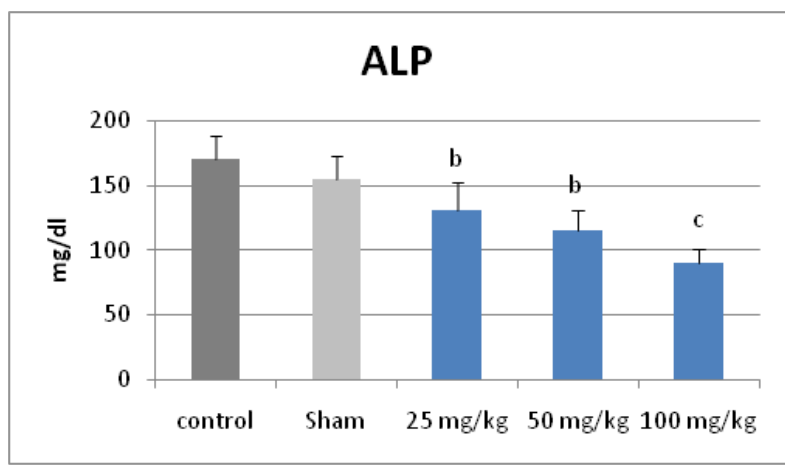

Figure 4 Effect of Tanacetum parthenium hydroalcoholic extract on Alkaline phosphatase (ALP) level in different groups of mice. Each value is expressed as the mean \pm S.E.M. of 6 animals. $b \mathrm{P}<0.0 \mathrm{I}$ and $\mathrm{c} P<0.00 \mathrm{I}$, compared to control and sham.

\section{Effect of tanacetum parthenium L. hydroalcoholic extract on liver enzymes}

As the results show, there is a significant decrease in ALP and AST level in all doses of extract $(25,50,1 \mathrm{nd} 100 \mathrm{mg} / \mathrm{kg})$, as compared with control and sham $(p<0.01$ and $p<0.001)$. However, $25 \mathrm{mg} / \mathrm{kg}$ dose of extract had no significant effect on AST level.

\section{Discussion}

In the present study, we examined the effect of Tanacetum parthenium hydroalcoholic extract on sexual hormones and liver enzymes. Results indicated that 50 and $100 \mathrm{mg} / \mathrm{kg}$ doses of extract decreased liver enzymes (AST and ALP) in the blood significantly. AS it is known, liver is the largest gland in the body and has various functions including; detoxification of blood, production of important factors, metabolizing medications or nutrients, and processing of waste products. Different factors such as toxins, drugs, alcohol and viruses can hurt the liver. AST and ALP tests are two-blood biochemical tests to evaluate liver function. ALP is an enzyme produced by liver cells and it helps to metabolize proteins. If the liver is damaged, ALP is released into the blood and this increases ALP level in the blood. ${ }^{9}$

The AST test also can be used to monitor a known liver disorder. It is usually measured together with ALP.AST is an enzyme found in various parts of the body especially muscle, heart, and liver. Elevated amounts of these enzymes may signal a liver problem. ${ }^{6}$ Hepatoprotection or antihepatotoxicity is the ability to prevent damage to the liver. It is documented that some herbs have hepatoprotective constituents. ${ }^{9-11}$ In our study, the feverfew extract showed hepatoprotective effects because the extract reduced AST and ALP enzymes concentration in the blood. Feverfew extract contains flavonoids like, kampferol, 
tanetin, apigenin, and luteolin. ${ }^{3}$ Flavenoids are phenolic compounds that have been indicated are able to provide liver protection. ${ }^{11}$ Amarowicz in 2009 showed that phenolic compounds extracted from the red lentil have antioxidant and antiradical capacity. ${ }^{13} \mathrm{Wu}$ in 2005 reported antioxidant properties for feverfew alcoholic extract and bioactive components especially, luteolin, apigenin and parthenolid. ${ }^{5}$ Antioxidants protect cell membrane from radical damage. The radical scavenging activity, prevent lipid peroxidation and normalize the lipid profile of hepatocyte membrane. ${ }^{11}$

In the other part of our study, the results shown, 50 and $100 \mathrm{mg}$ / $\mathrm{kg}$ doses of feverfew hydroalcoholic extract increased estrogen and progesterone levels in female NMRI mice. Feverfew extract contains flavonoids compounds. It is reported that, these compounds have some structural similarities to the natural estrogen estradiol, as well as other steroid hormone and steroid hormone antagonists. The extract contains flavonoids like luteolin and apigenin that indicated have strong estrogenicity and progestational activity, respectively. ${ }^{12}$ Flavonoids are phytoestrogens that can bind to estrogen receptors (ER $\alpha$ and $E R \beta$ ) and active many signaling pathways in estrogen-target cells. Phytoestrogens can be a favourable alterrnative to synthetic estrogen. ${ }^{7}$

\section{Conclusion}

This study demonstrates that Tanacetum partenium hydroalcoholic extract has potential hepatoprotective activity which may be due to its flavonoids in the extract but as it may affect on estrogen and progesterone hormone levels, enough precaution in consumption is necessary.

\section{Acknowledgments}

None.

\section{Conflicts of interest}

The author declares there are no conflicts of interest.

\section{References}

1. National center for complementary and alternative medicine. Feverfew. 2012.

2. Calopi G, Delbo M. Assessment report on Tanacetum parthenium (L.) Schulz Bip., herba. 2010. 40 p.

3. Pareek A, Suthar M, Rathore GS, et al. A systematic review. Pharmacogn Rev. 2011;5(9):103-110.

4. Nemati Karimooy H, Gholamnezhad Z, Talebi M. Effect of Tanacetum parthenium (feverfew) in treatment of migraine headache comparing to dihydroergotamine and placebo. AAPM Annual Meeting. 2011;5(9):10310 .

5. Wu C, Chen F, Wang X, et al. Antioxidant constituents in feverfew (Tanacetum parthenium) extract and their chromatographic quantification. Food Chem. 2005;96(2):220-227.

6. Reference ranges and what they mean. Lab Tests Online (USA). 2013.

7. Zand RSR, Jenkins DJA, Diamandis EP. Hormone activity of flavonoids and related compounds. Breast Cancer Res Treat. 2000;62(1):35-49.

8. National Institutes of Health. Guide for the care and use of laboratory animals. DHEW publication (NIH), revised. Bethesda: Office of Science and Health Reports, DRR/NIH; 1985. 246 p.

9. Kumar A. A review on hepatoprotective herbal drugs. IJPRC. 2012;2(1):92-102.

10. Baghbanan H, Sharifian A, Esmaeili S, et al. Hepatoprotective herbs, Avicina viewpoint. Iran Red Cres Med J. 2014;16(1):e12313

11. Dhiman RK, Chawla YK, Brinkhaus B, et al. Herbal medicine for liver diseases. Dgc Dis Sci. 2005;50(10):1807-1812.

12. Marino M, Galluzzo P. Is there an answere? Are flavonoids agonists or antagonists of the natural hormone $17-\beta$-Estradiol? IUBMB Life. 2008;60(4):241-44.

13. Amarowiz R, Estrella I, Hernandez T, et al. Antioxident activity of a red lentil extract and its fractions. Int J Mol Sci. 2009;10:5513-5527. 